Jurnal Sulolipu : Media Komunikasi Sivitas Akademika dan Masyarakat

Vol. 20 No.12020

e-issn : 2622-6960, p-issn : 0854-624X

\title{
Analisis Faktor Yang Berhubungan Dengan Kejadian Low Back Pain Di PT. Maruki International Indonesia Makassar
}

Adelia Suryani Jonathan ${ }^{1}$ dan Mulyadi $^{2}$

1,2Jurusan Kesehatan Lingkungan Poltekkes Kemenkes Makassar

email: adeliasuryanijonathan@yahoo.com

\begin{abstract}
Ergonomic is compatibility between working tools and workers who not suitable can cause workers to feel uncomfortable and decreased worker productivity. One of the things related to ergonomics is a work position. In this case such as long-standing, lifting, pushing, sitting position, etc. Workers of body activity that is not good in the long term will cause Low back pain (LBP) or Lower Back Pain (NPB). This study aimed to analyze the factors associated with the incidence of Low Back Pain in PT. Maruki International Indonesia Makassar. This research is an observational analytic study with a cross-sectional study design, a total sample of 58 people, and using a purposive sampling method, and data analysis is tested by conducting a statistical test that is chi-square. The results showed there was no relationship between age and the incidence of low back pain with $P$-value is $0.697>0.05$, there was a relation between duration time of work and the incidence of low back pain with P-value is $0.004<0.05$ and there was a relation between work ergonomics with the incidence of low back pain with $P$-value is $0.012<0.05$. Based on the results of this study concluded there ere no relation between the variables with the incidence of low back pain in workers at PT. Maruki International Indonesia Makassar in the factory section 1. Suggestions It is expected that workers improve their working methods of paying attention to health by applying ergonomic work principles to avoid injury and other occupational diseases.
\end{abstract}

Keywords: Low Back Pain, Age, Duration Of Work, Ergonomics

\section{ABSTRAK}

Ergonomi merupakan kesesuaian antara alat kerja dan pekerja yang tidak sesuai dapat menyebabkan pekerja merasa tidak nyaman dan produktivitas pekerja menurun. Salah satu hal yang berkaitan dengan ergonomi adalah posisi kerja. Dalam hal ini seperti lama berdiri, mengangkat, mendorong, posisi duduk, dsb. Aktivitas tubuh pekerja yang kurang baik dalam jangka waktu lama akan menyebabkan Low back pain (LBP) atau Nyeri Punggung Bawah (NPB). Tujuan Penelitian ini adalah untuk menganalisis faktor yang berhubungan dengan kejadian Low Back Pain di PT. Maruki International Indonesia Makassar.. Penelitian ini merupakan penelitian observasional analitik dengan desain cross sectional study, jumlah sampel sebanyak 58 orang dan menggunakan metode purposive sampling dan analisis data diuji dengan melakukan uji statistic yaitu chi square. Hasil penelitian menunjukkan tidak ada hubungan antara umur dengan kejadian low back pain dengan $\mathrm{P}$-value $0,697>0,05$, ada hubungan antara lama waktu kerja dengan kejadian low back pain dengan P-value 0,004 < 0,05 dan ada hubungan antara ergonomi kerja dengan kejadian low back pain dengan P-value $0,012<$ 0,05 . Berdasarkan hasil penelitian dapat disimpulkan bahwa tidak ada variabel yang berhubungan dengan kejadian low back pain pada pekerja di PT. Maruki International Indonesia Makssar dibagian factory 1. Sebaiknya para pekerja dapat memperbaiki teknik cara bekerja menerapkan prinsip kerja secara ergonomis agar terhindar dari cedera, dan penyakit akibat kerja lainnya

Kata Kunci: $\quad$ Low Back Pain, Umur, Lama Kerja, , Ergonomi Kerja.

\section{PENDAHULUAN}

International labour Organization (ILO), mendefinisikan ergonomi merupakan aplikasi ilmu pengetahuan biologi manusia dengan pengetahuan rekayasa untuk mencapai sejumlah penyesuaian dan timbal balik dari pekerja baik wanita maupun pria dalam melaksanakan pekerjaannya, manfaatnya dapat diukur dari efisiensi, kesehatan, dan kesejahteraan. (Kuswana. 2014).

Nyeri punggung merupakan keluhan yang sering dijumpai pada kehidupan sehari-hari. Diperkirakan hampir semua orang pernah mengalami nyeri punggung semasa hidupnya. Nyeri punggung bawah tetap menjadi beban kesehatan masyarakat yang utama diseluruh dunia industri, dari data epidemiologi menunjukkan nyeri punggung bawah masuk pada urutan yang ke 19 dengan presentase $27 \%$, dan prevalensi dirasakan seumur hidup sebanyak $60 \%$ (Demoulin 2012). Menurut World Health Organization (WHO), 2-5\% dari karyawan di negara industri tiap tahun mengalami nyeri punggung bawah, dan 15\% dari absenteisme di industri baja serta industri perdagangan disebabkan karena nyeri punggung bawah (Sakinah et al 2010 dalam liza 2014).

Berdasarkan data penyakit yang didapatkan dari PT. Maruki International Indonesia Makassar untuk penyakit otot dan kerangka pada tahun 2017 di Peroleh hasil Penyakit otot dan kerangka merupakan tertinggi ke 4 dari 18 jenis penyakit yang sering terjadi di PT. Maruki International Indonesia Makassar.

Hasil observasi awal yang dilakukan oleh peneliti pada pekerja di PT.Maruki International Indonesia Makassar, adapun masalah yang terlihat pada pengerjaan yaitu postur tubuh pekerja tidak sesuai dengan kaidah ergonomi, dimana posisi punggung saat bekerja terlalu banyak membungkuk, pandangan kearah benda kerja dan posisi leher terlalu menunduk dan posisi kaki pekerja dalam kondisi tertekuk. Hal ini mengakibatkan pekerja menjadi cepat lelah dan dalam waktu yang lama akan mengakibatkan gangguan musculoskeletal. Adapun keluhan pekerja yang dirasakan yaitu rasa nyeri pada bagian punggung. 
Jurnal Sulolipu : Media Komunikasi Sivitas Akademika dan Masyarakat

Vol. 20 No.12020

e-issn : 2622-6960, p-issn : 0854-624X

Berdasarkan hasil survey dan observasi yang dilakukan peneliti di PT. Maruki International Indonesia Makasssar peneliti akan melakukan penelitian yaitu " Analisis Faktor Yang Berhubungan Dengan Kejadian Low Back Pain di PT. Maruki International Indonesia Makassar".

\section{Bahan dan Metode}

\section{LokasiPenelitian:}

Penelitian ini dilakukan di Departemen Produksi PT. Maruki International Indonesia, Jalan Kapasa Raya Kawasan Industri Makassar, Kapasa, Tamalenrea, Kota Makassar.

\section{Desain dan Variabel Penelitian}

\section{a. Desain}

Jenis penelitian yang digunakan adalah penelitian observasi analitik dengan pendekatan Cross Sectional Study dimana variabel bebas dan terikat diamati dalam waktu yang bersamaan.

\section{b. Variabel Penelitian}

Variabel bebas dalam penelitian ini yaitu umur pekerja, ergonomi kerja, lama waktu kerja dan beban Kerja.Variabel terikat dalam penelitian adalah kejadian low back pain

\section{Populasi dan Sampel}

\section{a. Populasi}

Populasi yang diambil dalam penelitan ini adalah semua pekerja yang bekerja di PT. Maruki International Indonesia Makassar. Jumlah populasinya adalah 248 pekerja.

\section{b. Sampel}

Sebagai sampel penelitian dilakukan dengan cara purposive sampling dengan kriteria : bekerja di bagian factory 1 dan masa kerja $\geq 5$ tahun berjumlah 58 responden.

\section{Pengumpulan data}

\section{a. Data Primer}

Data primer adalah data yang langsung diperoleh pada PT. Maruki International Indonesia dan observasi melalui kuesioner dan wawancara langsung pada pekerja mengenai resiko kecelakaan kerja.

\section{b. Data Sekunder}

Data sekunder ini diperoleh dengan mengumpulkan data yang bersumber dari literaturliteratur, bahan kuliah, buku-buku dan hasil penelitian lainnya yang berhubungan dengan objek penelitian.

\section{c. Teknik Analisa Data}

Data yang telah diolah dan disajikan kemudian dianalisis secara statistik mengunakan uji chi square untuk mengetahui ada atau tidaknya hubungan umur, lama kerja, dan ergonomi keja dengan kejadian low back pain bagian Factory 1 di PT. Maruki International Indonesia Makassar

\section{HASIL PENELITIAN}

\section{Hubungan Umur Dengan Kejadian Low Back Pain}

Tabel 1.

Hubungan Umur Dengan Kejadian Low Back Pain pada

Pekerja PT. Maruki International Indonesia Makassar bagian Factory 1 Tahun 2019

\begin{tabular}{|c|c|c|c|c|c|c|c|}
\hline \multirow{3}{*}{ Umur } & \multicolumn{4}{|c|}{ Low Back Pain } & \multirow{3}{*}{ Total } & \multirow{3}{*}{$\%$} & \multirow{3}{*}{$\mathbf{P}$} \\
\hline & \multicolumn{2}{|c|}{$\begin{array}{c}\text { Ada } \\
\text { kejadian }\end{array}$} & \multicolumn{2}{|c|}{$\begin{array}{l}\text { Tidak ada } \\
\text { kejadian }\end{array}$} & & & \\
\hline & $\mathrm{N}$ & $\%$ & N & $\%$ & & & \\
\hline Muda & 43 & $74 \%$ & 7 & $12 \%$ & 50 & $86 \%$ & \\
\hline Tua & 7 & $12 \%$ & 1 & $2 \%$ & 8 & $14 \%$ & 0,697 \\
\hline TOTAL & 50 & $14 \%$ & 8 & $86 \%$ & 58 & 100 & \\
\hline
\end{tabular}

Sumber : Data Primer

Data yang ditunjukkan pada tabel 1 mempertihatkan bahwa responden dengan umur muda yang tidak ada keluhan dan tidak mengalam kejadian low back pain sebanyak 7 responden $(12 \%)$ dan umur tua 1 responden (2\%),sedangkan yang ada keluhan dan mengalami kejadian low back pain umur muda 43 responden (74\%) dan umur tua 7 responden (12\%)

\section{Hubungan Lama Waktu Kerja Dengan Kejadian Low Back Pain}

Tabel 2.

Hubungan Lama Waktu Kerja Dengan Kejadian Low Back Pain pada Pekerja PT. Maruki International Indonesia Makassar bagian Factory 1 Tahun 2019 Low Back Pain

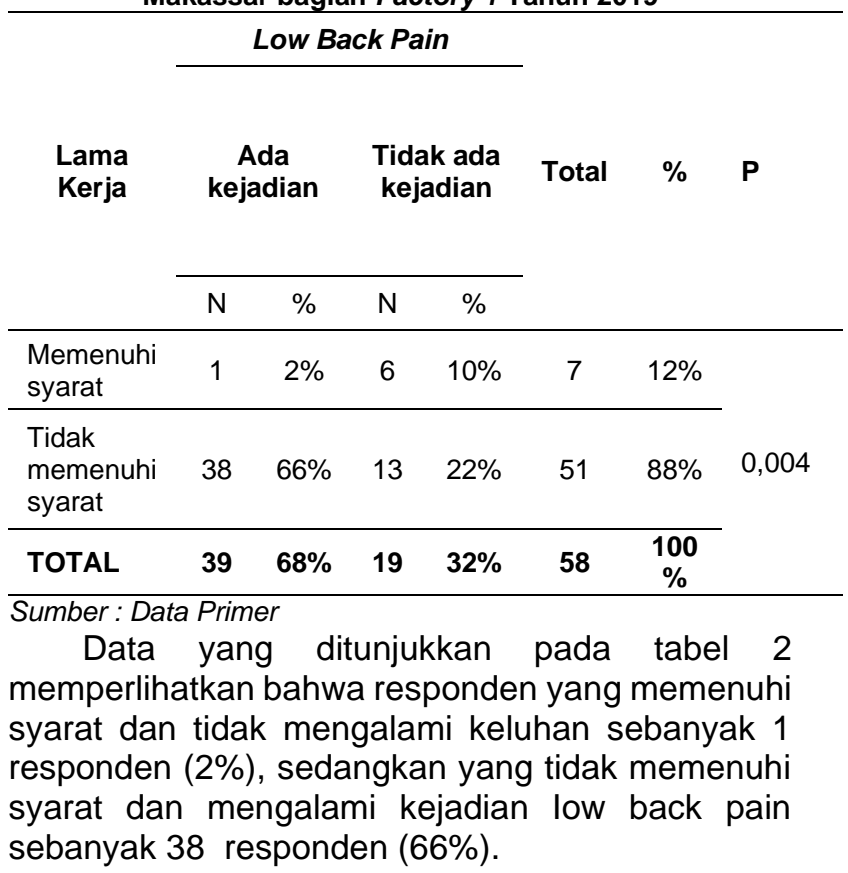


Jurnal Sulolipu : Media Komunikasi Sivitas Akademika dan Masyarakat

Vol. 20 No.12020

e-issn : 2622-6960, p-issn : 0854-624X

\section{Hubungan Antara Ergonomi Kerja dengan Kejadian Low Back Pain}

Tabel 3.

Hubungan Ergonomi Kerja Dengan Kejadian Low Back

Pain pada Pekerja PT. Maruki International Indonesia

Makassar bagian Factory 1 Tahun 2019

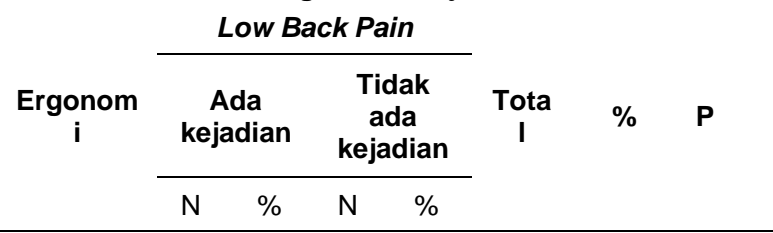

\begin{tabular}{|c|c|c|c|c|c|c|}
\hline $\begin{array}{l}\text { Memenu } \\
\text { hi syarat }\end{array}$ & $\begin{array}{l}1 \\
0\end{array}$ & $\begin{array}{l}17 \\
\%\end{array}$ & 0 & $0 \%$ & 10 & $17 \%$ \\
\hline $\begin{array}{l}\text { Tidak } \\
\text { memenu } \\
\text { hi syarat }\end{array}$ & $\begin{array}{l}2 \\
9\end{array}$ & $\begin{array}{l}50 \\
\%\end{array}$ & $\begin{array}{l}1 \\
9\end{array}$ & $\begin{array}{l}33 \\
\%\end{array}$ & 48 & $83 \%$ \\
\hline TOTAL & $\begin{array}{l}3 \\
9\end{array}$ & $\begin{array}{l}67 \\
\%\end{array}$ & $\begin{array}{l}1 \\
9\end{array}$ & $\begin{array}{l}33 \\
\%\end{array}$ & 58 & $\begin{array}{c}100 \\
\%\end{array}$ \\
\hline
\end{tabular}

Sumber: Data Primer

Dilihat dari tabel diatas, bahwa pekerja di bagian factory 1 sebanyak 10 responden $17 \%$ bekerja dengan posisi kerja yang ergonomi pada saat melakukan pekerjaan.

\section{PEMBAHASAN}

Beberapa faktor yang dijadikan Sebagai variabel dalam penelitian ini adalah faktor umur, lama kerja, dan ergonomi kerja. Berikut adalah pembahasan untuk masing-masing varibel yang di teliti :

\section{Hubungan Umur dengan Kejadian Low Back Pain}

Hasil Uji statistik dengan menggunakan Chi Square di peroleh $p=$ 0,697. Maka dapat disimpulkan bahwa $\mathrm{HO}$ diterima dan Ha ditolak yangartinya tidak ada hubungan antara umur dengan kejdian low backpain pada pekerja di PT.Maruki International Indonesia Makassar bagian factory 1.

Artinya ada faktor lain yang lebih dominan yang menyebabkan terjadinya low back pain pada pekerja tersebut, diketahui bahwa masa kerja untuk sebagian pekerja tersebut lebih lama dari 5 tahun, yang berarti juga merupakan faktor risiko tambahan untuk terjadinya LBP. Tidak ditemukannya hubungan antara faktor risiko umur dan kejadian LBP.
2. Hubungan Lama Waktu Kerja dengan Kejadian Low Back Pain

Hasil uji statistik dengan menggunakan $\mathrm{Chi}$ Square diperoleh nilai $p=0,04 \quad(p<0,05)$. Dengan demikian dapat disimpulkan bahwa HO ditolak dan Ha diterma yang artinya ada hubungan antara lama waktu kerja dengan kejadian low back pain pada pekerja di PT. Maruki Inernational Indonesia Makassar bagian factory 1.

Lamanya seseorang bekerja dengan baik dalam sehari sekitar 6-8 iam dan sisanya untuk beristirahat atau berkumpul dengan keluarga. Dalam seminggu orang bisa bekerja dengan baik selama 40 jam yang dapat dibagi dalam 5 atau 6 hari kerja. Lebih dari itu akan kecenderugan timbulnya hal-hal yang negative.

3. Hubungan Ergonomi Kerja dengan Kejadian Low Back Pain

Hasit analisis data menggunakan uji chi square diperoleh nilai $p=0,012(p<0.05)$, maka dapat disimpulkan bahwa Ho ditolak dan Ha diterima yang artinya ada hubungan antara ergonomi kerja dengan kejadian low back pain pada pekerja di PT. Maruki International Indonesia Makassar bagian factory 1 .

\section{KESIMPULAN}

Berdasarkan hasil pembahasan tentang Analisis Faktor yang Berhubungan dengan Kejadian Low Back Pain maka dapat disimpulkan bahwa ketiga variabel penelitian yaitu Umur, Lama waktu kerja dan ergonomi kerja hanya umur memiliki hubungan terhadap kejadian low back pain

\section{SARAN}

1. Diharapkan kepada para pekerja agar memperbaiki teknik cara bekerja memperhatikan kesehatan dengan menerapkan prinsip kerja secara ergonomis agar terhindar dari cedera, dan penyakit akibat kerja lainnya.

2. Diharapkan bagi para pekerja untuk sering melakukan peregangan otot ketika merasakan kram atau sakit pada bagian tubuh serta melakukan olahraga yang teratur dan makan makanan yang banyak mengandung gizi. 
Jurnal Sulolipu : Media Komunikasi Sivitas Akademika dan Masyarakat

Vol. 20 No.12020

e-issn : 2622-6960, p-issn : 0854-624X

\section{DAFTAR PUSTAKA}

Andri, Tri. 2018. Hubungan Posisi Duduk Dengan Intensitas Low Back Pain Pada Buruh Pabrik Rokok PT. Cakra Guna Cipta Kabupaten Malang. Karya Tulis IImiah (online) diakses pada 8 Januari 2019s http://repository.poltekkes-soepraoen.ac.id/72/2/3\%20BAB\%20l.pdf

Anies. 2005. Penyakit Akibat Kerja. Jakarta: PT Elex Media Komputindo.

Bimaariotejo. 2009. Low Back Pain (LBP). diakses 8 Januari 2019 https://bimaariotejo.wordpress.com/2009/07/07/low-back-pain-lbp/

Eko.A. Widodo. 2017. Masa Kerja, Sikap Kerja dan Keluhan Low Back Pain Pada Pekerja Bagian Produksi PT. Surya Besindo Sakti Serang. Laporan Penelitian. (online) Diakses pada 8 Januari 2019 http://eprints.uad.ac.id.

Giring Novrianto. 2016. Hubungan Teknik Mengangkat Beban Dengan Keluhan Nyeri Punggung Bawah Pada Pekerja Angkut Beras Di Pasar Makale Tahun 2015. Makassar: Fakultas Kesehatan Masyarakat Universitas Hasanuddin (Skripsi tidak dipublikasikan).

Giri. Wiarto. 2017. Nyeri Tulang dan Sendi. Yogyakarta: Gosyen Publishing.

Hoetomo. 2005. Kamus Lengkap Bahasa Indonesia. Surabaya: Mitra Pelajar.

Husnhy. Rasta. Manja 2013. Penyakit Akibat Kerja (online). diakses pada 7 Januari 2019 husnirafikha.blogspot.com/2013/11/penyakit-akibat-kerja.html

Kuswana. Sunaryo Wowo. 2017. Ergonomi dan K3 Kesehatan Keselamatan Kerja. Bandung: PT Remaja Rosdakarya. Cetakan Ketiga.

Liza F.L. Djauhar.ismail, Titih huriah.2014 Medula Spinalis Belt (MSB) Terhadap Penurunan Nyeri Penderita Nyeri Punggung Bawah pada Pekerja Batu Bata. Laporan hasil penelitian. Universitas Muhammadiyah Yogyakarta. Yogyakarta (online). diakses pada 8 Januari 2019 https://media.neliti.com/media/publications/228949-medula-spinalis-belt-msb-terhadap-penuru1b9fe301.pdf

Musdalifah. 2014. Teknik Angkat Beban Dengan Keluhan Low Back Pain (LBP) Pada Pekerja Di PT. IKI Kota Makasssar. Makassar (Online) Diakses 7 Januari 2019 http://digilib.unhas.ac.id/opac/detailopac?id=14669. 